\title{
ACEPTABILIDAD SOCIAL, FORMA URBANA Y SUSTENTABILIDAD DE BARRIOS URBANOS EN Ciudad Juárez, Chimuahua
}

\author{
Claudia Gabriela Vargas Fernández \\ Marisol Rodríguez Sosa ${ }^{* *}$
}

\section{Resumen}

En el campo de la planificación urbana, el cuestionamiento sobre la sustentabilidad y la posibilidad de la planificación sostenible ha dado lugar a un conjunto de replanteamientos y discusiones que repercuten en los estudios sobre forma urbana y modos de vida sostenibles. Este abordaje presenta un conjunto de variables al respecto de la sustentabilidad de la ciudad desde la unidad de análisis del barrio. En ese sentido, el presente artículo propone el análisis de tres barrios urbanos de vivienda de interés social en Ciudad Juárez, Chihuahua (México), integrando aspectos de la forma urbana y la aceptabilidad social, con el propósito de comprender la relación entre las dimensiones física y sociocultural que se desprende del concepto de sustentabilidad urbana.

Palabras clave: vivienda de interés social, aceptabilidad de la forma urbana, desarrollo urbano sustentable.

* MSc Planificación y Desarrollo Urbano, Estudiante de Doctorado, Universidad Autónoma de Ciudad Juárez, Ciudad Juárez (México). [claudiagabrielavargas@gmail.com]

** PhD en Urbanismo, Docente-Investigador y coordinadora del Programa de Diseño Urbano y del Paisaje, Universidad Autónoma de Ciudad Juárez, Ciudad Juárez (México). [marisolrs@gmail.com]

Recibido: 30 de mayo de 2016 / Modificado: 12 de septiembre de 2016 / Aceptado: 1 de septiembre de 2016

Para citar este artículo

Vargas Fernández, C. G., Rodríguez Sosa, M. (2016). Aceptabilidad social, forma urbana y sustentabilidad de barrios urbanos en Ciudad Juárez, Chihuahua. opera, 19, pp. 111-137.

DOI: http://dx.doi.org/10.18601/16578651.n19.07 
SOCIAL ACCEPTABILITY URBAN FORM

AND SUSTAINABILITY IN URBAN NEIGHBORHOODS IN CIUDAD JUÁREZ, CHIHUAHUA

\section{Abstract}

In the field of urban planning, questioning around sustainability and the possibility of sustainable urban planning has led to a new set of approaches and discussions that impact studies on urban form and sustainable livelihoods. This approach characterized the work presented by Mike Jenks and Colin Jones (2010), Dimensions of the Sustainable City, where a set of variables are presented about urban sustainability from the neighbourhood level of analysis. In that sense, this article proposes the analysis of three social housing neighborhoods in Ciudad Juárez, Chihuahua, México, integrating aspects of urban form and social acceptability, in order to understand the relationship between the physical and sociocultural dimensions of the concept of urban sustainability.

Key words: Social housing, acceptability of urban form, sustainable urban development.

\section{INTRODUCCIÓN}

La idea de la sustentabilidad, de modo general, propone la necesidad de un desarrollo equilibrado entre tres aspectos en especial: lo económico, el medioambiente y lo sociocultural. En ese sentido, en el debate sobre la sustentabilidad urbana ya es lugar común el estudio de variables económicas, geográficas, sociales, la biodiversidad, el transporte y la movilidad, el uso de las energías renovables y no renovables. Sin embargo, existen pocos estudios que hayan profundizado en la consideración de la forma urbana, desde la inclusión no solo de los elementos físicos de la ciudad, sino también de la "aceptabilidad social" de la misma y el impacto que ello puede tener en el diseño de los barrios urbanos que promuevan o no estilos de vida sostenibles. Es sobre ese tema que nos invitan a reflexionar Mike Jenks y Colin Jones (2010), en Dimensions of the Sustainable City, donde se plantea la importancia de estudiar la aceptabilidad social de la forma urbana.

La profundización en el tema de la forma urbana resultó del interés inicial por los principios del concepto de "arcología", propuesto por el arquitecto Paolo Soleri y la posibilidad de su aplicación en la planificación urbana de Ciudad Juárez. Soleri señaló, a través de esa noción, la necesidad de unir la ecología y el proceso de creación de la forma, enfocándose especialmente en la densidad, es decir, en las diferencias entre una ciudad compacta y una expandida en lo que se refiere a los recursos naturales, como ha sido destacado por Andruscavage (2007):

El concepto de arcología fue desarrollado por el arquitecto Paolo Soleri, donde él presenta dentro de la ciudad una fusión dada entre la ecología y la arquitectura. Este concepto propone una forma urbana altamente integrada y compacta tridimensional que es lo contrario a la expansión urbana con su consumo intrínsecamente inútil de la tierra, la energía y el tiempo, tiende a aislar a las personas y las comunidades entre sí. La complejidad 
y la miniaturización de la ciudad permiten la conservación radical de la tierra, energía y recursos.

Este concepto es uno entre muchos otros en los que se destacan los valores o beneficios de la ciudad compacta, lo cual nos señaló la importancia de entender esta noción dentro del conjunto de teorías de la sustentabilidad porque, como señala Jenks, tienen una misma base: "La teoría de la ciudad compacta se basa de la misma fuente de ideas de la 'sustentable', 'eco' y 'Ciudad verde'. Esto hace también referencia a las visiones 'arcológicas' de Paolo Soleri (1987)" (Jenks, 2000).

La arcología propone la creación de un "hábitat armonioso", es decir, se concentra en la sustentabilidad desde el nivel de la comunidad, de ahí que pone el reto de pensar en la unidad del barrio como contenedor de una posible comunidad sustentable. Partiendo de ello, se evidenció la importancia del estudio de la sustentabilidad, pero desde el nivel de barrio y en los aspectos de la forma urbana (tipologías, densidad, accesibilidad, servicios, equipamientos, edificaciones) que pueden incidir en la sustentabilidad de la misma. El barrio es la unidad básica de crecimiento urbano en Ciudad Juárez, donde el habitante construye su noción del lugar que habita dentro de la urbe. En ese sentido, se estudiaron tres barrios de Ciudad Juárez, considerando aspectos socioculturales y urbanos, con el propósito de comprender la relación entre la sustentabilidad urbana y las variables de la forma urbana y la aceptabilidad social. El propósito final del estudio es proponer estrategias para el desarrollo urbano sustentable de Ciudad Juárez desde la unidad del diseño urbano de los barrios, en particular aquellos de viviendas de interés social que son responsables por una buena parte del crecimiento urbano de la ciudad.

Uno de los elementos principales del proceso de planteamiento de la forma urbana de una ciudad o de una comunidad es la variable de la densidad poblacional, la cual nos puede aproximar o alejar del ideal de la ciudad compacta que ha sido señalado en muchos ensayos sobre la sustentabilidad urbana. En ese sentido, estudiar la densidad es clave para dirigirnos hacia la posibilidad de plantear estrategias de desarrollo urbano sustentable.

El comportamiento de la densidad de población en Ciudad Juárez refleja el crecimiento expansivo y disperso que ésta ha tenido en las últimas cinco décadas, el cual ha sido paralelo al crecimiento poblacional y la incorporación de suelo a la mancha urbana. El crecimiento urbano de Ciudad Juárez se disparó a partir de la década de los sesenta, con en un promedio de 300 hectáreas anuales en el periodo de 1960 a 1990, llegando a 1037 hectáreas anuales de 1995 al 2000, para bajar a 423,35 hectáreas en los siguientes cinco años y retomar la explosividad a 2456 hectáreas en tan solo tres años -de 2005 a 2008-, como se observa en la figura 1 (IMIP, 2010).

A pesar de la tendencia a la disminución de la densidad poblacional que se observa desde los años setenta, en la última década el desarrollo de programas federales y estatales de vivienda de interés social ha sido el principal justificante para aprobar la ampliación del fundo legal y así poder abastecer los rezagos de vivienda e infraestructura contemplados por el municipio, como lo menciona el Plan 
114

FIGURA 1. CRECIMIENTO HISTÓRICO DE CIUDAD JUÁREZ, 1856-2000

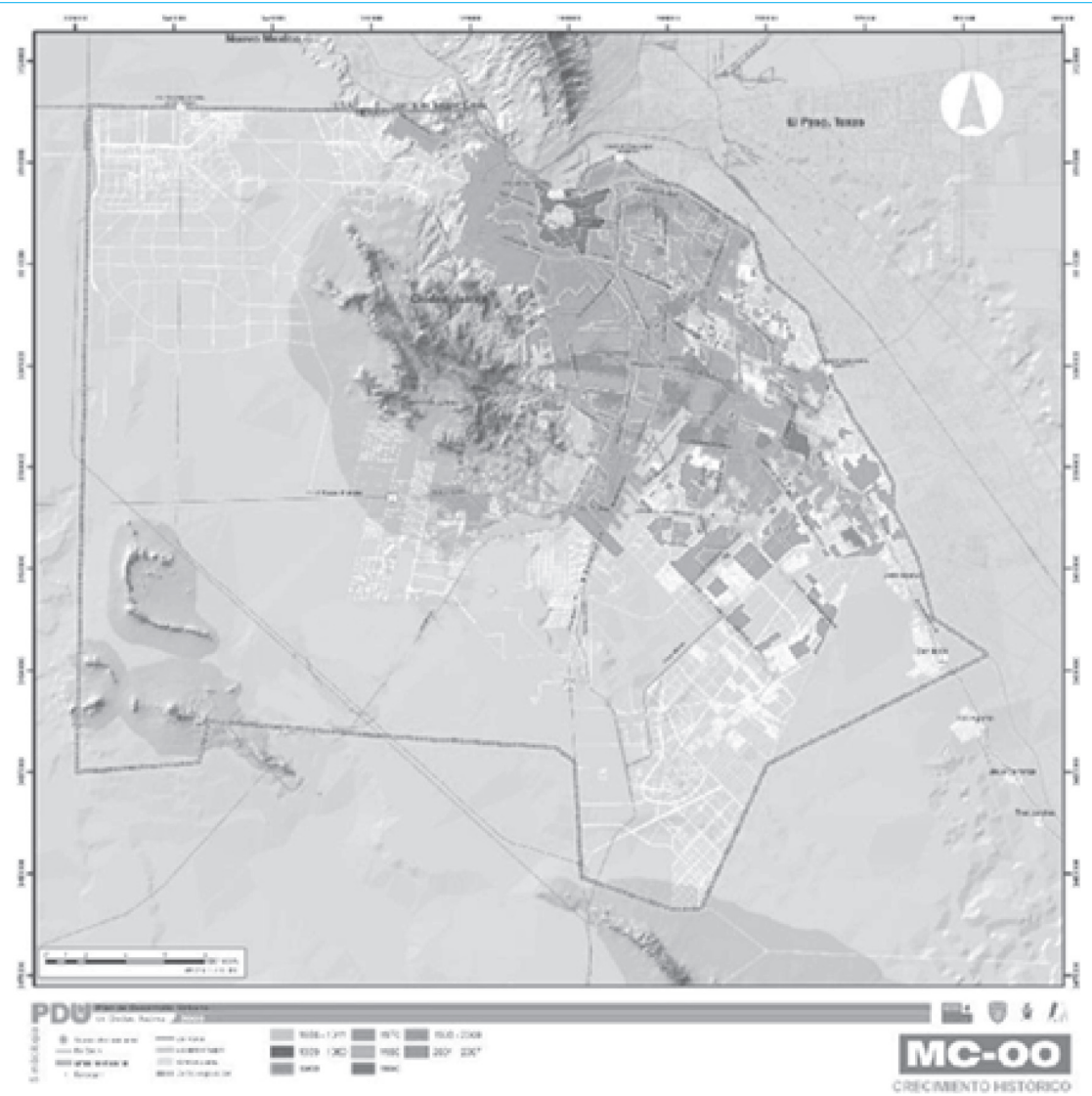

\begin{tabular}{|c|c|c|c|c|c|}
\hline Año & Población & Superficie $(\mathrm{Ha})$ & Densidad (Hab./Ha & Incremento $(\mathrm{Ha})$ & N.$^{\circ}$ de Ha anuales \\
\hline 1856 & 4.342 & 10.45 & 460.93 & & \\
\hline 1894 & 7.582 & 63.74 & 124.12 & 53.29 & 1.40 \\
\hline 1911 & 11.289 & 127.44 & 94.71 & 63.7 & 3.75 \\
\hline 1939 & 48.881 & 379.14 & 86.75 & 251.7 & 22.88 \\
\hline 1950 & 122.566 & 909.22 & 153.21 & 530.08 & 48.19 \\
\hline 1960 & 262.119 & 3.064 .37 & 215.08 & 2.155 .15 & 215.52 \\
\hline 1970 & 407.370 & 5.899 .63 & 97.13 & 2.835 .26 & 283.53 \\
\hline 1980 & 544.496 & 10.795 .11 & 60.63 & 4.895 .48 & 489.55 \\
\hline 1990 & 789.522 & 14.049 .30 & 65.17 & 2.835 .26 & 325.42 \\
\hline 1995 & 995.770 & 15.363 .74 & 56.42 & 1.314 .44 & 262.89 \\
\hline 2000 & 1.208 .498 & 20.553 .00 & 57.46 & 5.189 .77 & 1.037 .85 \\
\hline 2005 & 1.301 .452 & 22.684 .77 & 57.37 & 2.131 .77 & 426.35 \\
\hline 2008 & 1.371 .494 & 30.052 .89 & 42.00 & 7.368 .12 & 2.456 .04 \\
\hline
\end{tabular}

Fuente: elaboración propia con datos censales extraídos del INEGI y del PDU CDJ 2010 (IMIP, 2010). 
Director de Desarrollo Urbano (PDU) de Ciudad Juárez en su versión 2010:

En los últimos años, la ciudad ha sido receptora de múltiples programas de impulso a la vivienda de los gobiernos federal y estatal requiriendo una expansión del territorio urbanizado, por lo que resultó estratégicamente necesario y factible solicitar la ampliación del fundo legal y límite del centro de población para poder aplicar estos recursos federales, situación que se formalizó el $1^{\circ}$ de septiembre del 2007 publicando el Decreto correspondiente en el Periódico Oficial del Gobierno del Estado (IMIP, 2010).

El crecimiento que el municipio de Juárez ha tenido en el periodo entre 1990 a la fecha ha sido el más notable. Partiendo de esta problemática, se busca identificar qué relación existe entre los aspectos de la forma urbana y la aceptabilidad social, y en qué medida esta relación es responsable por la existencia o no de barrios urbanos sustentables en distintas regiones morfológicas en Ciudad Juárez (central, intermedia y periférica). Particularmente se cuestiona qué niveles de aceptabilidad social existen en los barrios (central, intermedio y periférico) seleccionados en Ciudad Juárez.

Se parte del supuesto de que la forma urbana (las tipologías de cuadras, lotes, edificaciones, la accesibilidad, los patrones de densidad y uso de suelo, y el acceso a servicios y equipamiento), y la aceptabilidad social (sentido de pertenencia, interacción social, y modos de vida sustentables, cercanía de equipamientos y servicios), están directamente relacionados y son un elemento esencial para plantear estrategias que nos guíen hacia la sustentabilidad urbana, en el sentido de que propician procesos que pueden favorecer o no el desarrollo sustentable de los barrios de Ciudad Juárez.

\section{OBJETIVO}

Identificar en qué medida la forma urbana y la aceptabilidad social inciden en la sustentabilidad urbana en Ciudad Juárez, en particular, en la unidad o escala del barrio, a través del análisis de tres barrios de vivienda media-baja en Ciudad Juárez (construidos en distintos momentos y localizados en distintas regiones de la estructura intraurbana). Se presentan variables que pudieron ser medidas y comparadas en la escala planteada. Se busca contribuir a la elaboración de normatividades conscientes sobre la importancia del desarrollo sustentable sociourbano de los barrios y las comunidades urbanas.

\section{METODOLOGÍA}

Se partió de la consideración de una serie de conceptos necesarios para alcanzar el objetivo de este análisis y ver qué aplicación tendrían en Ciudad Juárez, basándose en cinco líneas de estudio planteadas: las dimensiones de la ciudad sustentable, barrios centrales en proceso de degradación en Ciudad Juárez, desarrollo de nuevos barrios de vivienda en áreas intermedias y periféricas, normatividad en cuanto al desarrollo urbano sustentable y análisis morfológico con sistemas de información geográfica. El estudio planteado es de tipo comprensivo y correlacional, pues busca 
comprender las relaciones entre distintas dimensiones del desarrollo urbano sustentable, a partir del estudio de varios barrios tomados como casos de estudio, que abarquen los requerimientos para ser analizados.

La propuesta planteada nos lleva al análisis comprensivo-correlacional en los barrios seleccionados como casos de estudio, partiendo de dos ejes de interpretación: 1) los elementos de la forma urbana y 2) los aspectos de aceptabilidad social. Así como una aproximación metodológica que se basa en el desarrollo y la aplicación de análisis de la forma urbana y espacial, cuestionarios y análisis documental (figura 2).

Para el análisis de la forma urbana se emplea una metodología que incluye el análisis de unidades morfotipológicas (tipología de las edificaciones, cuadras, lotes, accesibilidad, espacios públicos), a partir de trazas digitales y datos plasmados en los sistemas de información geográfica (mediante el programa ArcMap 10).

Retomando a Horacio Capel, y para hacer más comprensivo este análisis, se cita el modo en el que él hace referencia al estudio morfológico:

El estudio morfológico puede tener objetivos puramente descriptivos y explicativos, y ayudar a entender la forma como las ciudades se han construidos y evolucionado. También puede tener objetivos normativos, en cuanto que a partir del análisis morfológico puede mejorarse el diseńo de la ciudad, al conocer menor el comporta-

FIGURA 2. ARRIBA: ESQUEMA DEL ANÁLISIS COMPRENSIVO-CORRELACIONAL; ABAJO: ESQUEMA TEÓRICO METODOLÓGICO

\begin{tabular}{|l|}
\hline \multicolumn{1}{|c|}{ Elementos formales } \\
\hline - Densidad \\
- Accesibilidad \\
- Uso de suelo \\
- Tipologías (cuadras, lotes, \\
edificaciones) \\
- Servicios y equipamento \\
\hline
\end{tabular}

Aceptabilidad social

- Modos de vida sustentable

- Sentido de comunidad y pertenencia

- Interacción social

\begin{tabular}{|l|}
\hline \multicolumn{1}{|c|}{ Teórico } \\
\hline - Forma urbana y \\
aceptabilidad social \\
- Sustentabilidad y \\
planificación urbana \\
- Estado del arte en Ciudad \\
Juárez
\end{tabular}

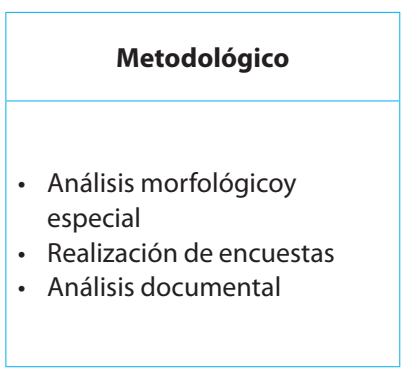


miento de los elementos componentes y los procesos de transformación de la ciudad (Capel, 2002).

En la investigación morfológica, es decir, de la forma urbana, se emplearon diversos niveles de análisis:

1. Tipología de lotes (tipos de lotes existentes en términos de área y forma).

2. Tipología de cuadras (dimensiones y forma de la cuadra).

3. Tipología de edificaciones (diversidad de tipos).

4. Equipamiento y espacios públicos (equipamiento público por zona, calidad y tipo de los espacios públicos, consolidación de centros de barrio, cuantificación de lotes baldíos).

5. Vialidades y accesos (clasificación de vialidades en tres niveles: primarias, secundarias y locales, requerimiento mínimo y patrones de accesibilidad).

6. Niveles de vulnerabilidad social y seguridad urbana (nivel de seguridad urbana con que cuentan los tres barrios a partir del análisis de Morales Cárdenas et al., 2013).

La vertiente de investigación que busca comprender la aceptabilidad social de los distintos barrios nos lleva a un análisis que exige la aplicación de encuestas con los habitantes de cada comunidad y, posteriormente, su procesamiento en el programa spss. Para la aplicación de los cuestionarios se consideró el total de la población de los tres barrios, lo que arroja la necesidad de tomar una muestra de 347 casos, de los cuales se aplicó un tamaño proporcional de la muestra a cada una de las tres colonias, cuya distribución quedó así: 105 cuestionarios en La Chaveña, 60 en Infonavit Casas Grandes y 182 en Parajes de Oriente. El análisis y la sistematización de los resultados se realizaron en el programa spss 19.

Para poder llegar a un análisis de las dimensiones sociales, la técnica de la encuesta mediante la aplicación de cuestionarios es pieza clave dentro del análisis, tal como lo indica López:

La encuesta se ha convertido en una herramienta fundamental para el estudio de las relaciones sociales. Las organizaciones contemporáneas, políticas, económicas o sociales, utilizan esta técnica como un instrumento indispensable para conocer el comportamiento de sus grupos de interés y tomar decisiones sobre ellos. Debido a su intenso uso y difusión, la encuesta es la representante por excelencia de las técnicas del análisis social (2008, p. 33).

El esquema que se maneja dentro de las encuestas deriva de la necesidad de conocer el modo de vida que tienen los habitantes dentro de su barrio, entre otros aspectos, y se divide en cuatro líneas de enfoque: 1) forma urbana-vivienda, 2) espacios públicos y apropiación del espacio, 3) accesibilidad y 4) aceptabilidad social.

\section{Selección de los casos de estudio}

Como casos de estudio se presentan tres barrios en tres distintas regiones morfológicas de la ciudad que permitan analizar diversos momentos del crecimiento urbano a lo largo del siglo xx, que han marcado la consolidación 
de las partes central, intermedia y periférica de la ciudad. Esto con el fin de comprender aspectos formales como su densidad, accesibilidad, presencia de servicios y equipamientos que sirvan a la comunidad, entre otros, y aspectos de aceptabilidad social como la percepción del usuario, así como el arraigo que tenga el habitante con el mismo.

El barrio es uno de los componentes con más arraigo al espacio de la ciudad y que es muestra de la diversidad cultural que se hace presente dentro de ella. Sin embargo, definir la noción de barrio es complejo, debido a la amplitud de significados, tanto físicos como simbólicos que carga, como seńala Moreno (2008):

Como primer acercamiento se puede definir barrio desde su origen etimológico, la palabra misma señala que puede entenderse tanto como "aldea" o "lo popular". Su concepción es múltiple, porque no solo se entiende como un espacio físico (territorio), sino que también como un espacio sociológico (lo popular), esta será una temática recurrente dentro de la definición de barrio en el que ambas tendencias se entremezclan.

El barrio, o la colonia, término más usado en nuestra sociedad, representa una unidad que ha marcado el proceso de crecimiento de nuestras ciudades. Aunque actualmente el término resulta un tanto confuso, pues la noción de colonia se ha venido diluyendo, en Ciudad Juárez ha sido un elemento de expansión y ampliación urbana esencial desde el siglo XX en adelante. A inicio del siglo xx Ciudad Juárez creció básicamente a partir de la adición de nuevas colonias, pero hoy en día, la presencia de fraccionamientos privados, así como de interés social, han fracturado la percepción de la ciudad en términos de sus barrios. Por tanto, es difícil partir de una definición espacial abstracta del barrio, y en ese sentido, lo más adecuado, según Bazant, es buscar comprender lo que el habitante identifica como la zona que habita:

La colonia o barrio se refiere a la zona urbana en que habitamos, y tiene diversas formas de definirla. Desde un punto de vista urbano sería aquel segmento de la ciudad que tiene similar patrón urbano de calles, características de edificaciones y densidad, o sea morfología urbana; pero puede o no coincidir con los límites arbitrarios asignados de la colonia por un código postal o un distrito electoral (Bazant, 2008).

$\mathrm{Al}$ analizar el mapa del crecimiento urbano de Ciudad Juárez y textos que documentan la historia y el proceso de crecimiento de la ciudad, se evidenció la presencia de tres fases muy importantes en la expansión de la ciudad.

La primera y más prolongada en el tiempo transcurre desde su fundación en 1659 hasta 1960, que coincide con lo que hoy se conoce como el centro tradicional o antiguo de la urbe. La segunda, de 1960 a 1990, es marcada por la expansión de la ciudad a raíz de la pesada llegada de la industria maquiladora; y la tercera y última gran fase sería la comprendida entre 1990 y la actualidad, marcada por la expansión de la periferia urbana como parte de la urbanización de grandes fraccionamientos de Infonavit y otros organismos de apoyo al financiamiento de la vivienda, que ha sido acompañada por la instalación de nuevas industrias en áreas cada vez más alejadas del centro fundacional. 
Para poder establecer un análisis comparativo de los resultados se seleccionaron en estas tres regiones tres barrios urbanos que albergan estratos de la población con niveles de ingresos bajos y medios bajos, y que fueron construidos como resultado de propuestas oficiales de expansión. Se escogieron para estudios de casos como ejemplo: 1) del área del centro tradicional (1658-1960) el barrio La Chaveña, 2) del área intermedia en el proceso de expansión por la llegada de la maquiladora (1960-1990) el Infonavit Casas Grandes, y 3) del área periférica marcada por la construcción de vivienda de interés social y maquiladoras, Parajes de Oriente.

Estos barrios no son resultado de crecimientos espontáneos o invasiones, sino que surgen a partir de políticas o intervenciones del Gobierno en turno enfocadas en la ampliación del número de viviendas para la población. En el caso de La Chaveña, fue resultado de la aprobación de la urbanización del "partido" del mismo nombre a inicios del siglo xx; y en el caso de los Infonavit Casas Grandes y Parajes de Oriente, ambos son consecuencia de la construcción de fraccionamientos residenciales promovidos por Infonavit. El Infonavit Casas Grandes es un fraccionamiento construido hace ya varias décadas bajo políticas anteriores de dicho órgano, y el Infonavit Parajes de Oriente es un ejemplo del modelo actual de gestión de Infonavit (figura 3).

\section{La Chaveña}

Dentro de la selección y delimitación del área morfológica central se optó por trabajar con uno de los barrios o colonias que tiene más historia y representatividad dentro de Ciudad Juárez, del que se tiene aún la concepción de que está en el "centro" de la ciudad, dado que por un largo periodo sí lo fue. La Chaveña, que actualmente cuenta con una superficie de $709.211,99 \mathrm{~m}^{2}$, fue fundada en el año de 1881. Dentro de la importancia que tiene este barrio para la ciudad, se puede citar que alberga dentro de ella hitos y elementos históricos y culturales, como la histórica "pila de la Chaveña”, la escuela "Revolución", el mercado informal de los "Cerrajeros", la clínica no. 47 del IMss, entre otras. Cuenta con una población total de 5603 habitantes, una superficie total de 70,9 ha, y un total de 1336 viviendas, lo que arroja una densidad promedio bruta de 79 habitantes por ha y de 18,8 viviendas por ha.

\section{Infonavit Casas Grandes}

Conjunto que según el Plan de Desarrollo Urbano fue creado en los ańos ochenta. Actualmente, este barrio es el encargado de asistir a miles de usuarios con su equipamiento y servicios, ya que cuenta con un gran número de comercios, bancos, escuelas, iglesias, avenidas y dos puntos muy importantes: la clínica 35 del imss y su punto de reunión de transporte urbano, así como el otro punto de salidas y llegadas de transporte en el centro comercial Plaza Juárez Mall, siendo estos elementos icónicos dentro de nuestra ciudad. Cuenta con una población total de 12.334 habitantes, en una superficie de 116,1 ha, y un total de 4400 viviendas, lo que arroja una densidad promedio bruta de 106 habitantes por ha y 37,9 viviendas por ha. 


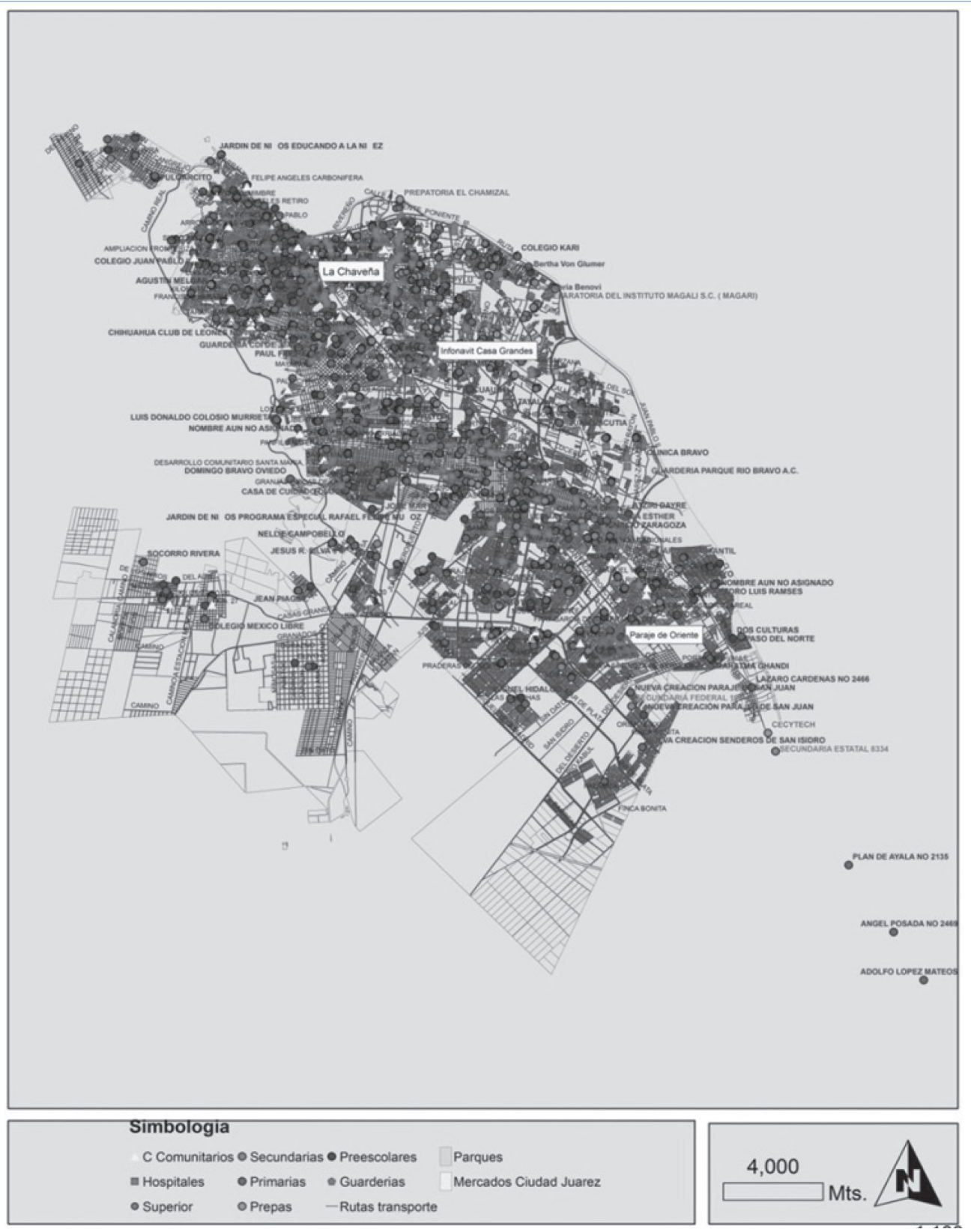

Fuente: elaboración propia con datos del INEGI y PDU. 


\section{Parajes de Oriente}

De reciente creación, según el PDu del 2010, fue para el 2006 aproximadamente cuando comenzó la creación de este conjunto habitacional. Se encuentra catalogado dentro de vivienda de interés social. Cuenta con una población total de 17.206 habitantes, en una superficie de 155,09 ha, con un total de 5349 viviendas, lo que arroja una densidad promedio bruta de 110,9 habitantes por ha y 34,5 viviendas por ha.

\section{SUSTENTABILIDAD, FORMA URBANA Y ACEPTABILIDAD SOCIAL: ABORDAJE TEÓRICO}

La idea de poner límites al crecimiento surge con el debate en torno al desarrollo sustentable a raíz de la urgencia en disminuir el consumo de recursos naturales. En las décadas de los setenta y ochenta la noción de sustentabilidad se planteó de modo inicial en encuentros como el Club de Roma (1972) y la Comisión sobre el Medio Ambiente y el Desarrollo de la que se desprende el Informe Brundtland (1987), en el que se define por primera vez de forma oficial la sustentabilidad como: "satisfacer las necesidades de la presente generación sin comprometer la habilidad de futuras generaciones para satisfacer sus propias necesidades" (Hardoy, 1992, en Sachs, 1994).

Las discusiones en torno al medioambiente y desarrollo promovidas por la Organización de las Naciones Unidas (ONU), en especial el Programa Agenda 21, es también un hito importante en el proceso de debate, donde se maneja el desarrollo sostenible como tema esencial de una agenda de interés mundial. Mailhold señala también el peligro que el crecimiento urbano impone a la posibilidad de un desarrollo sustentable, haciendo especial énfasis en el caso de la insustentabilidad urbana que se hace cada vez más presente en las ciudades latinoamericanas:

El crecimiento descontrolado de las ciudades ha traído consigo graves problemas de abasto, contaminación del agua y del aire, dificultades para la eliminación de los desechos sólidos, y ha acrecentado el riesgo de accidentes industriales. Las grandes ciudades latinoamericanas se han convertido en un medio hostil, en el que predominan las aéreas de asentamientos precarios, carentes con frecuencias de los servicios públicos más elementales. $\mathrm{Su}$ sistema circulatorio interno está dominado por el automóvil privado, que absorbe una cantidad enorme de espacio y energía, en beneficio exclusivo de un sector que representa menos del 10\% de la población regional (Maihold y Urquidi, 1990).

En ese sentido, destacamos la conexión entre el pensamiento de Paolo Soleri (1969) y la idea de "arcología", con los principios de la sustentabilidad urbana, pues Soleri también subraya la importancia de entender la interacción entre los diversos sistemas de la ciudad, con el objetivo de disminuir el efecto urbano, o sea, la expansión, pues aboga por la compacidad como estrategia para promover una mayor interacción entre los distintos organismos y entidades:

La teoría de la arcología sostiene que esta delgadez se puede obtener solo a través de la reducción intrínseca al efecto urbano, la compleja interacción entre diversas 
entidades y organismos que marcan los sistemas de salud tanto en el mundo natural y en todas las ciudades con éxito y de importancia cultural en la historia.

Los factores morfológicos de la ciudad son aquellos que tienen la capacidad de dar pie a la interacción social, resultan un instrumento clave para la planificación urbana y han sido estudiados desde principios del siglo xx; de estos se desprenden algunas relaciones con factores que no se creería tienen afinidad pero que, tal como Mumford lo mencionó e hizo hincapié, la interacción social es pieza clave para promover el desarrollo urbano racional:

Limitaciones en el tamaño, la densidad y el área son absolutamente necesarios para la interacción social efectiva, y por lo tanto, los instrumentos más importantes de la planificación económica racional y cívica.

\section{$[\ldots]$}

La ciudad en su sentido más completo, entonces, es un plexo geográfico, una organización económica, un proceso institucional, un teatro de acción social, y un símbolo estético de unidad colectiva (Mumford, 1937).

En la búsqueda de la implementación de las bases para el desarrollo sustentable en las ciudades, es necesario entender qué papel juega la forma urbana para que esta a su vez propicie o dificulte el mismo, así como comprender el alcance que esta pueda tener. Entendiendo que el estudio morfológico en este caso, cumple con la tarea de describir e interpretar el modo en que tres diversas áreas se han constituido dentro de la ciudad.

\section{RESULTADOS}

El proceso de análisis nos permitió llegar a varias conclusiones que se presentan a continuación de manera sistematizada, incorporando el resultado obtenido para un mismo tema en los diversos ejes de investigación.

\section{Forma urbana de barrios (diversidad tipológica)}

Se observó una diferencia importante en las características de la forma urbana del barrio central (de expansión tradicional y edificaciones construidas por sus habitantes) frente a los barrios de localización intermedia y periférica (diseñados y edificados por constructoras para vivienda social). Se puede resumir que:

a) En el barrio central se detectó mayor diversidad de usos de suelo y equipamiento público, de tamaño y tipos de lotes y viviendas.

b) En los barrios intermedios y periféricos se observó menor diversidad de usos de suelo y equipamiento público, y de tamaño, y tipos de lotes y viviendas.

En La Chaveña, la tipología de lotes predominante está en el rango de $120 \mathrm{~m}^{2}$ y menor, siguiendo los de 151 a $180 \mathrm{~m}^{2}$, e incluso varios con más de $251 \mathrm{~m}^{2}$, contando en ese sentido una mezcla variada de tipos y tamaños de lotes. Predominan las manzanas que cubren una superficie de hasta $4000 \mathrm{~m}^{2}$, y una forma urbana regular característica de una expansión urbana natural del tejido del centro urbano tradicional de la ciudad. El 
barrio presenta un trazado ortogonal distribuido en forma de espinas de pescado que se encuentran en el eje principal, la calle 5 de Febrero (figura 4 a y d).

En el Infonavit Casas Grandes, predominan los lotes de hasta $120 \mathrm{~m}^{2}$, con algunas zonas con lotes de 151 a $180 \mathrm{~m}^{2}$, y los de más de $211 \mathrm{~m}^{2}$ corresponden a áreas de donación y parques. De modo que se puede decir que, comparado con La Chaveńa, presenta mayor densidad habitacional y menor mezcla variada de tamaños y tipos de lotes. Predominan las manzanas que cubren una superficie hasta los 4000 metros cuadrados. Se trata de una forma urbana semirregular y proyectada, con una mezcla de calles curvas y lineales, que crean núcleos de viviendas dentro del barrio (figura $4 \mathrm{~b}$ y e).

En Parajes de Oriente predominan las manzanas que cubren una superficie de los 4000 a $8000 \mathrm{~m}^{2}$, abarcando una gran cantidad de lotes en cada manzana. Se recurre al proyecto de una forma urbana donde predominan las líneas curvas y las manzanas estrechas y alargadas, cuya planta aérea asemeja o vende la idea de un "suburbio americano", pero sin ofrecer las amenidades de ese estilo de vida ${ }^{1}$ (figura $4 \mathrm{c} \mathrm{y} \mathrm{f).}$

\section{Densidad poblacional, hacinamiento y abandono de vivienda}

Como ideal, las ciudades deben ser más compactas en sus zonas centrales e ir dismi- nuyendo la densidad hacia las afueras con el propósito de mantener una transición entre la ciudad y el campo, que favorezca la preservación de los procesos ecológicos y ambientales. Sin embargo, el estudio permitió detectar que en Ciudad Juárez se observa un proceso contrario. Se identificó un aumento de la densidad hacia la periferia, es decir, el barrio central es el que cuenta con menor densidad, le sigue el intermedio y el periférico es el que presenta mayor densidad.

a) barrio central: es menor la densidad y el hacinamiento, hay mayor cantidad y diversidad de equipamiento público y espacio público, mayor reconocimiento e identificación por parte de los habitantes, mayor diversidad de opciones de vivienda con la posibilidad de renta, mayor comercio de barrio, menor deseo de abandono.

b) intermedio y periférico: se detectó mayor densidad y hacinamiento, menor diversidad de usos de suelo y de tamaño, y tipos de lotes y viviendas, menor cantidad y diversidad de equipamiento público y espacio público, aunque ambiguamente existe mayor espacio disponible para esos usos en las áreas de dotación, menor diversidad de opción de vivienda y renta, mayor deseo de abandono.

Considerando el total de población y superficie de cada barrio, la densidad bruta se incrementa desde el centro hacia los barrios

1 Debido a que la creación relativamente nueva de Parajes de Oriente, no fue posible localizar la base de datos por lote de esta zona, para fines ilustrativos, se anexa el mapa anterior, donde dentro de una sección de manzanas de Parajes de Oriente (referida posteriormente dentro de este apartado) una sección elaborada marcada con los colores rojo y azul, donde se muestra la tipología y distribución de lotes. 
$1 2 4 \longdiv { 1 }$
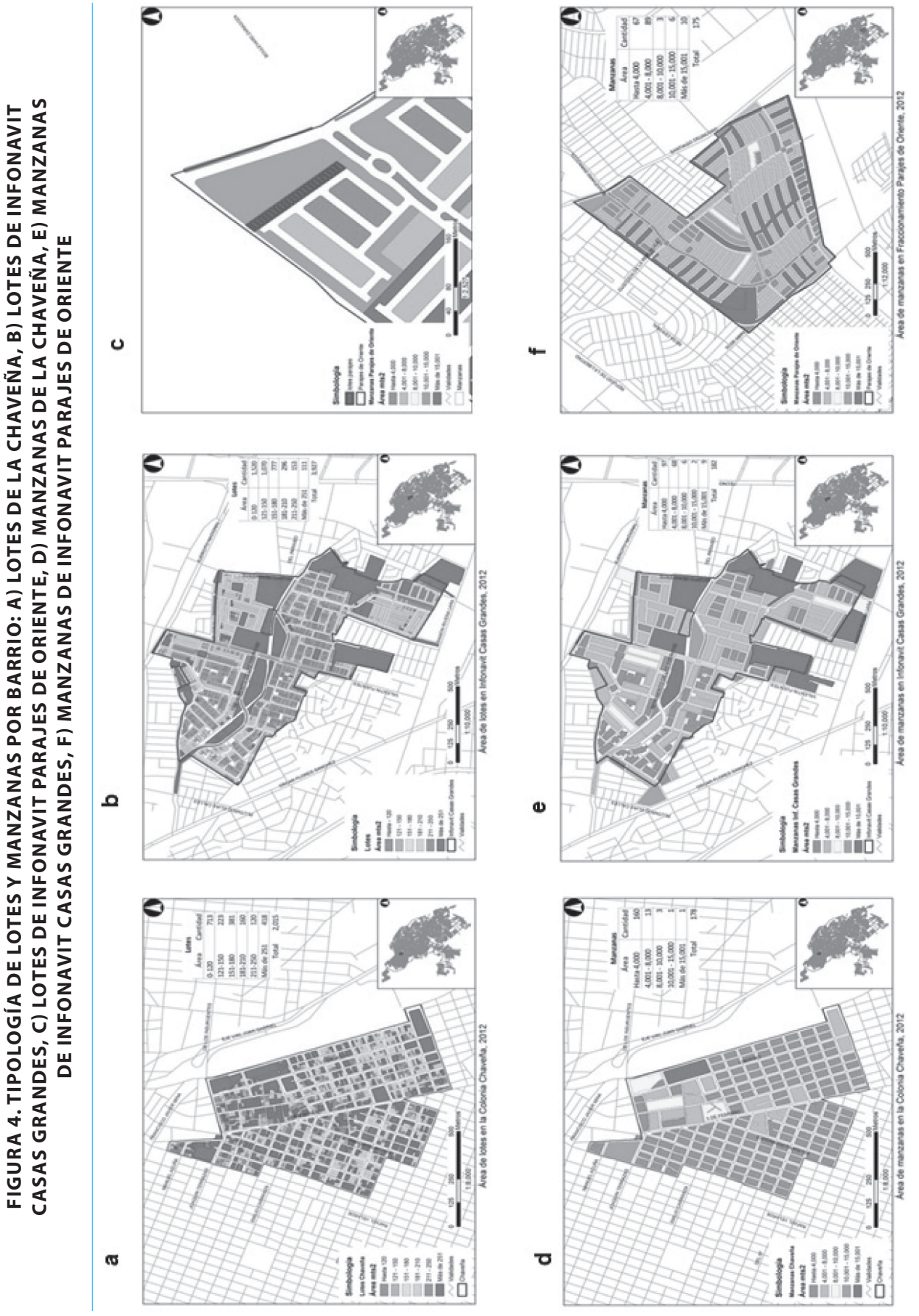

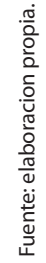


más periféricos, lo cual no es lo más deseable: La Chaveña con 79 hab/ha (5603 habitantes en 70,9 ha), Infonavit Casas Grandes con 106 hab/ha (12.334 habitantes en 116,1 hectáreas) e Infonavit Parajes de Oriente 110,9 ha/ha (17.206 habitantes en 155,09 ha). Según el Plan de Desarrollo Urbano (2010), La Chaveña cuenta con un promedio de 0,86 habitantes por por habitación, el Infonavit Casas Grandes, un promedio de 0,66 habitantes por habitación y Parajes de Oriente, con un promedio de 1,28 habitantes por habitación. Parajes de Oriente, comparado con La Chaveña e Infonavit Casas Grandes, es el barrio de mayor densidad y hacinamiento, lo cual es contradictorio considerando que este es el único barrio que se encuentra en el suburbio de la ciudad, donde hay menor restricción de espacio urbano (figura 5).

Se identificó además que la densidad poblacional y el índice de hacinamiento se comportan igual. Es decir, hay menor hacinamiento en el barrio central y el periférico es el que presenta mayor hacinamiento. Al comparar los barrios central e intermedio (La Chaveña, Infonavit Casas Grandes) con el periférico (Parajes de Oriente), se observó una disminución del número de habitaciones, acompañado de un aumento del índice de hacinamiento (La Chaveña, 0,86 habitantes por cuarto; Infonavit Casas Grandes, 0,66 habitantes por cuarto, y Parajes de Oriente, 1,28 habitantes por cuarto). A pesar de que las zonas centrales e intermedia más consolidadas no presentan índices de hacinamiento, sin embargo, el barrio más reciente, situado en el cinturón periférico, ya presenta índices de hacinamiento, a pesar de estar localizado en zona urbana con mayor disponibilidad de terreno en el momento de su construcción, y de haber sido diseñado a partir de políticas de vivienda más modernas y planificadas.

Por medio de las encuestas se identificó que en el barrio central y más antiguo se presenta mayor número de viviendas en renta, mientras que en el más reciente, la única opción de vivienda es la compra, y la renta no alcanza índices relevantes. En ese sentido, en los barrios de construcción más reciente en la zona periférica de la ciudad hay menos opción de renta, lo cual obliga a los residentes a mantener un compromiso de largo plazo con dicha propiedad.

Por otro lado, al comparar la densidad y el índice de hacinamiento con el nivel de abandono de vivienda se comprobó que el barrio central cuenta con menor densidad y hacinamiento y menor nivel de abandono, y el periférico con mayor densidad, hacinamiento y mayor población afectada por el abandono de vivienda (en La Chaveña el 30,6\% de las viviendas se encuentran abandonadas, en Infonavit Casas Grandes el 13,7\% y en Parajes de Oriente el 21,6\%), de modo que se puede decir que, en gran medida, el nivel de hacinamiento y el nivel de abandono de viviendas son directamente proporcionales. Lo más alarmante es que Parajes de Oriente es el barrio de construcción más reciente, con menos de 10 ańos de inauguración, lo cual no deja dudas sobre el fracaso en términos de aceptabilidad social de la política actual de vivienda. Así, la densidad y el hacinamiento se presentan como una gran debilidad que afecta profundamente el nivel de aceptabilidad social del barrio, asociado al abandono de vivienda. 
126
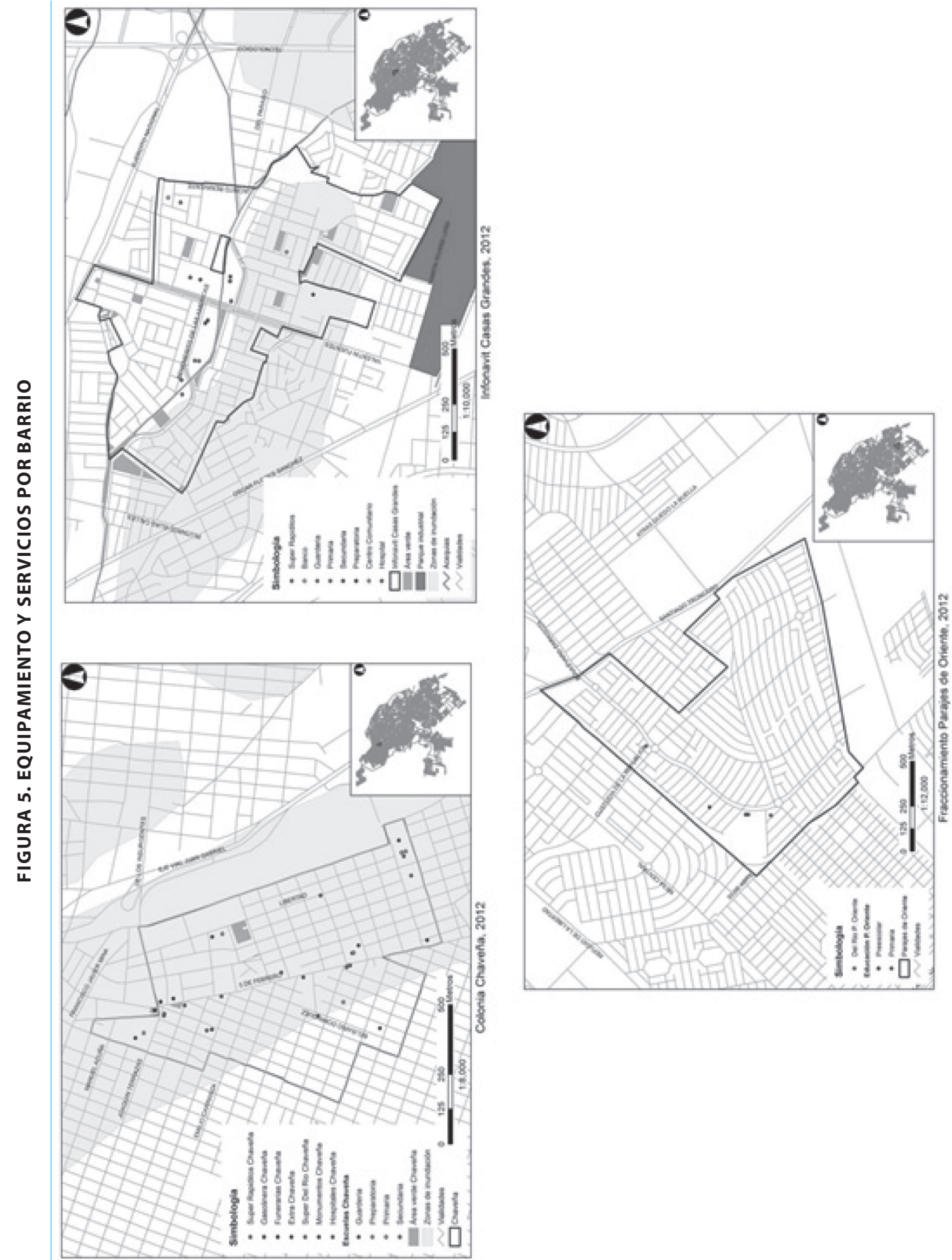


\section{Apropiación del espacio público y calidad del espacio urbano}

La diversidad parece ser nuevamente la clave, pues aunque hay mayor cantidad de terreno dedicado a ello en los barrios intermedio y periférico, se identificó mayor diversidad y apropiación por parte de los habitantes (orgullo, uso, reconocimiento) en La Chaveña. Se verificó que 67,6\% de los habitantes de La Chaveña afirman que les gustan los espacios públicos abiertos que existen en su barrio; en Infonavit Casas Grandes respondieron afirmativamente el 53,3\% de los habitantes y en Parajes de Oriente solo el 13,7\% manifiesta sentir agrado por este tipo de lugares. El resul- tado en Parajes de Oriente es un poco grave, sobre todo, considerando que es el barrio más reciente, con más población y mayor nivel de hacinamiento, donde los habitantes necesitan aún más de un lugar de esparcimiento como complemento a la vivienda. En el caso se La Chaveña, los habitantes usan el lugar para ocio y se sienten identificados con el espacio público como un símbolo que caracteriza su barrio, y en Infonavit Casas Grandes realizan actividades deportivas y mantienen cierta convivencia, cosa que no ocurre en Parajes de Oriente, donde los usuarios expresaron sentirse intimidados por los maleantes que frecuentan estos espacios, así como por el grave deterioro de los mismos (figura 6).

FIGURA 6. RESULTADOS DE ESPACIOS PÚBLICOS ABIERTOS

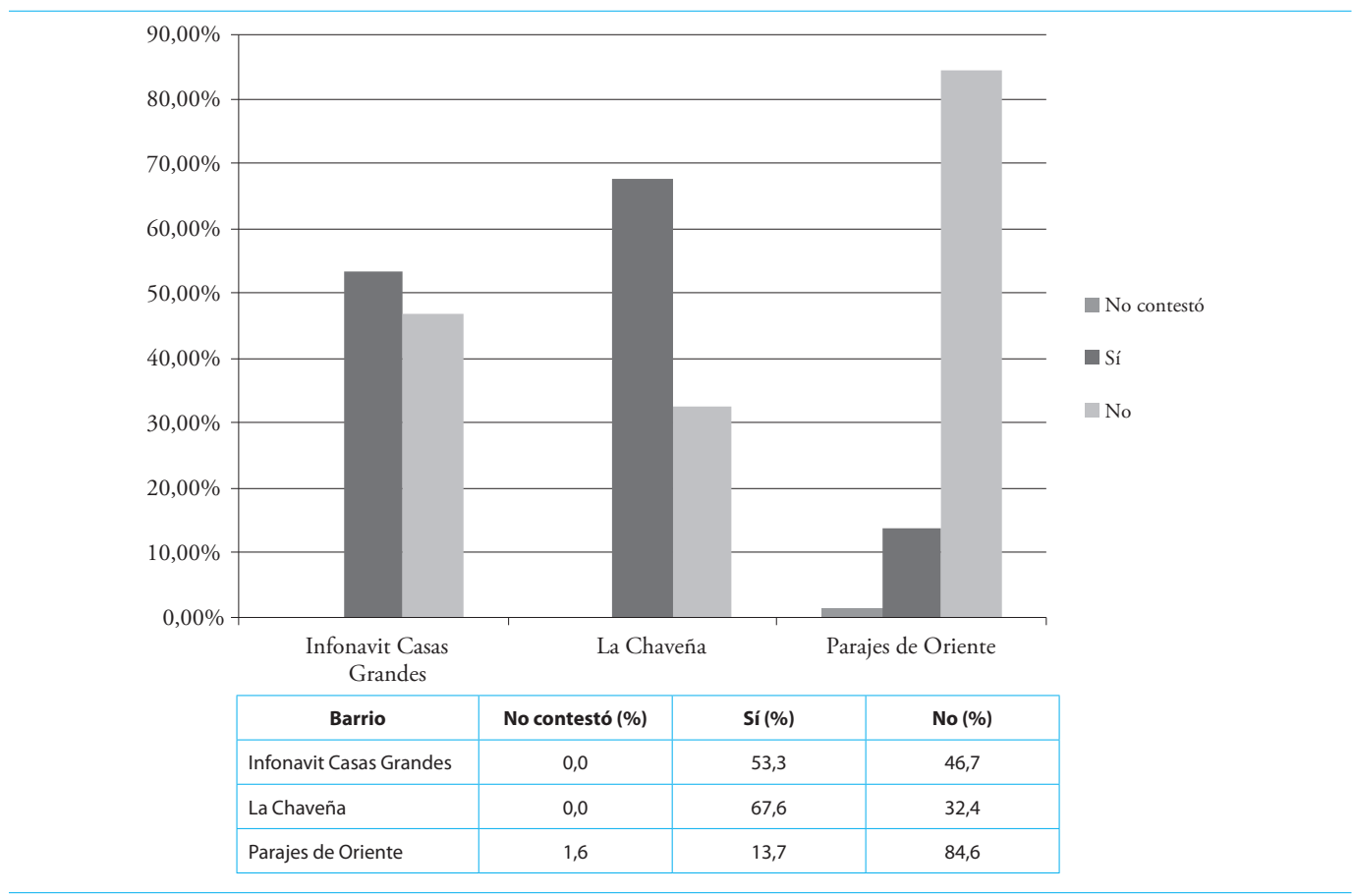

Fuente: elaboración propia. 
Acompańando el resultado sobre los espacios públicos, la calidad del espacio urbano representa un gran desafío en los tres barrios, especialmente en el localizado en la zona periférica. En Infonavit Casas Grandes, el $46,7 \%$ de la población no está satisfecha con la calidad de las calles y banquetas, y por la presencia de baldíos; este porcentaje aumenta a $61 \%$ en La Chaveña y en Parajes de Oriente alcanza el $81,3 \%$ de la población (figura 7 ).

\section{Equipamiento, servicios urbanos y usos del suelo}

Este aspecto parece seguir la misma lógica del espacio público, la cantidad y sobre todo la diversidad de oferta parecen ser la clave, pues aunque en términos de la dotación recomendada por Sedesol, los tres barrios cumplen, si no en su interior, al menos en un radio de 30 minutos, en La Chaveńa no solo hay cantidad, sino diversidad de equipamiento, oferta que disminuye en $50 \%$ en el barrio intermedio y en alrededor de un $90 \%$ en el barrio periférico: en La Chaveña existen 30 facilidades de servicios y equipamientos (hospitales, escuelas, parques, supermercados, funerarias, comercios, entre otros), el Infonavit Casas Grandes cuenta con 15 facilidades de este tipo y Parajes de Oriente, solo con 5 facilidades (una tienda de conveniencias Del Río, dos preescolares y dos primarias). Esta población, de 7063 ha-

FIGURA 7. CALIDAD DEL ESPACIO PÚBLICO URBANO

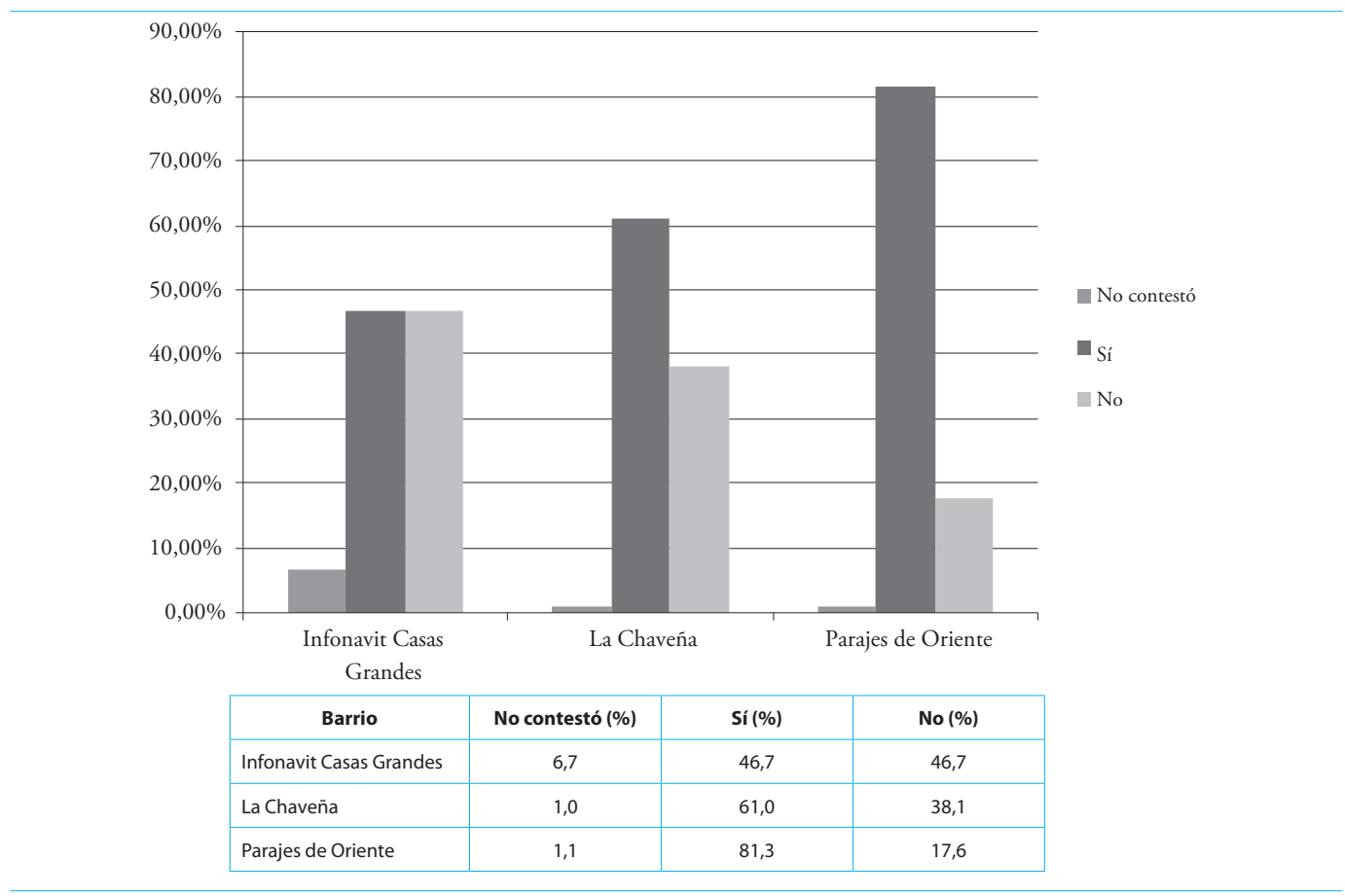


bitantes, no cuenta con ningún servicio de salud o puesto de socorro en la proximidad.

Sobre el tema del uso de suelo es relevante analizar las demandas de la población en términos de equipamiento urbano. Es de destacar que los habitantes manifestaron la necesidad de que exista en su barrio mayor cantidad y diversidad de equipamiento, sobre todo de muchos de los pertenecientes a los subsistemas de Sedesol de cultura, y recreación y deporte, o relacionados con esas actividades. En particular, se señaló el deseo de contar con parques, gimnasios, salón de baile, cine, biblioteca, centro comercial, de modo que la población pide una mayor intensidad de usos recreativos, deportivos, culturales y comerciales, lo que se puede interpretar como una necesidad de promover zonas con usos mixtos o centros de barrios con opciones diversas. Esto resulta de gran relevancia, considerando que muchos de estos barrios, sobre todo Infonavit Casas Grandes y Parajes de Oriente, son conjuntos habitacionales desarrollados desde un modelo de planificación y diseño urbano basado mayormente en el monouso del suelo, con predominio del uso de suelo habitacional, que ha dado lugar a una "periferia dormitorio" en Ciudad Juárez. En ese sentido, cobra importancia la necesidad de mayor atención a cuidados de la forma y del diseńo urbano de estos barrios, a la incorporación de criterios de composición urbana basados en el uso mixto, en la creación de centros de barrio que agreguen la vida urbana comunitaria.

En términos de la dotación de servicios básicos de infraestructura urbana (agua potable, drenaje, gas natural y LP, energía eléctrica) se encuentra un buen nivel de cobertura en los tres barrios, aunque aún es evidente que Parajes de Oriente es el más rezagado; sin embargo, donde se observó mayor carencia fue en lo relativo a los servicios urbanos que no son básicos o de sobrevivencia, pero que miden la calidad de vida de la población en términos de la accesibilidad a la comunicación, información y entretenimiento, como son el teléfono, la televisión por cable y la Internet. Se detectó que el barrio con mejores índices de calidad de vida en cuanto a comunicación y acceso a la información es Infonavit Casas Grandes, y hay mayor rezago en Parajes del Oriente y La Chaveña.

\section{Identidad comunitaria, arraigo y exclusión}

Se encontró que existe una relación entre los elementos formales de la ciudad, en este caso a nivel escala de barrio, y la pertenencia, aceptabilidad y permanencia en los barrios con más antigüedad (de los casos de estudio), en especial con relación a algunos de los elementos simbólicos como los parques, plazas o escuelas, que son parte de lo que los habitantes y usuarios de estas zonas hacen referencia en su vida diaria. El contexto inmediato es el referente que los usuarios siempre solían mencionar y hacer remembranzas, así como contar anécdotas o hacer sugerencias, porque es donde llevan a cabo la mayoría de sus actividades. El estudio del nivel de identificación de los habitantes con sus barrios arrojó que en La Chaveña el 88,6\% de los encuestados se sienten identificados con su barrio, y en Infonavit Casas Grandes el 61,7\%; sin embargo, en Parajes de Oriente solo el 35,7\% 
dicen identificarse, o sea, aproximadamente 4541 habitantes no se identifican con el lugar en que residen. La relación que existe en estos resultados coincide con el tiempo de creación que tienen los barrios, en el sentido de que se observa mayor identificación de los habitantes con el barrio más antiguo, donde es de destacar que los habitantes han construido sus viviendas a su gusto, a diferencia de Infonavit Casas Grandes y Parajes de Oriente, ambos barrios desarrollados a partir de tipologías arquitectónicas y de diseño urbano apoyadas por las políticas de vivienda de los últimos cuerenta años, donde es más limitada la posibilidad de la autogestión y autoconstrucción de las viviendas por parte de sus propietarios. Este resultado se corroboró con la pregunta acerca de si les gusta su barrio, donde el resultado es semejante, o sea, acompaña el tiempo de creación de dichos barrios: respondieron afirmativamente un $90 \%$ de los encuestados en La Chaveña, seguido de Infonavit Casas Grandes donde se alcanza un $68,3 \%$ y solo $28,6 \%$ en Parajes de Oriente (figura 8).

Una cuestión que se destacó en los cuestionarios fue que en la mayoría de las respuestas los encuestados de Parajes de Oriente se mostraron inconformes con las características y cualidades de su barrio, y estaban más dispuestos a mudarse. Incluso, y como dato interesante, algunos de los encuestados del barrio periférico solían ser habitantes de los barrios central e intermedio respectivamente, a lo cual, ante la pregunta de si regresarían a vivir a su antiguo barrio el cien por ciento (de los encuestados que contestó bajo estas características) contestó que sí. Entre las respuestas mencionaron que estaban mejor en ellos porque eran más céntricos, se identificaban más entre otros, lo cual prende los focos de atención para detectar qué es lo que está pasando con los conjuntos habitacionales que se están creando últimamente, ¿por qué es tan complicado que los usuarios tengan cierto sentido de pertenencia o apego a su barrio (aceptabilidad social)? Sobre el deseo de mudarse del barrio los resultados arrojan que en La Chaveña el 24,8 \% lo haría, en Infonavit Casas Grandes el 36,7\% y en Parajes de Oriente el arrollador 70,3\% de los encuestados, lo cual permite inferir que a aproximadamente 837 habitantes de Infonavit Casas Grandes, 1192 de La Chaveña y 4965 de Parajes de Oriente les gustaría mudarse de sus casas. El número en Parajes de Oriente es tan alto que permite señalar sin dudas que el desarrollo de este conjunto habitacional es un total fracaso en términos de aceptabilidad social.

Otro resultado relevante en términos del nivel de aceptabilidad social de los habitantes es la percepción de inclusión o exclusión, sobre lo cual se identificó que en Infonavit Casas Grandes y La Chaveña la población se siente mayormente incluida, mientras los habitantes de Parajes de Oriente se sienten excluidos. La aceptabilidad social no se puede medir con las estadísticas, solo se alcanzan a comprender a través de la encuesta, al estudiar cómo viven y sienten los habitantes, de ahí la importancia de estas técnicas y herramientas de análisis para los estudios urbanos en general. 
FIGURA 8. IDENTIDAD CON EL BARRIO

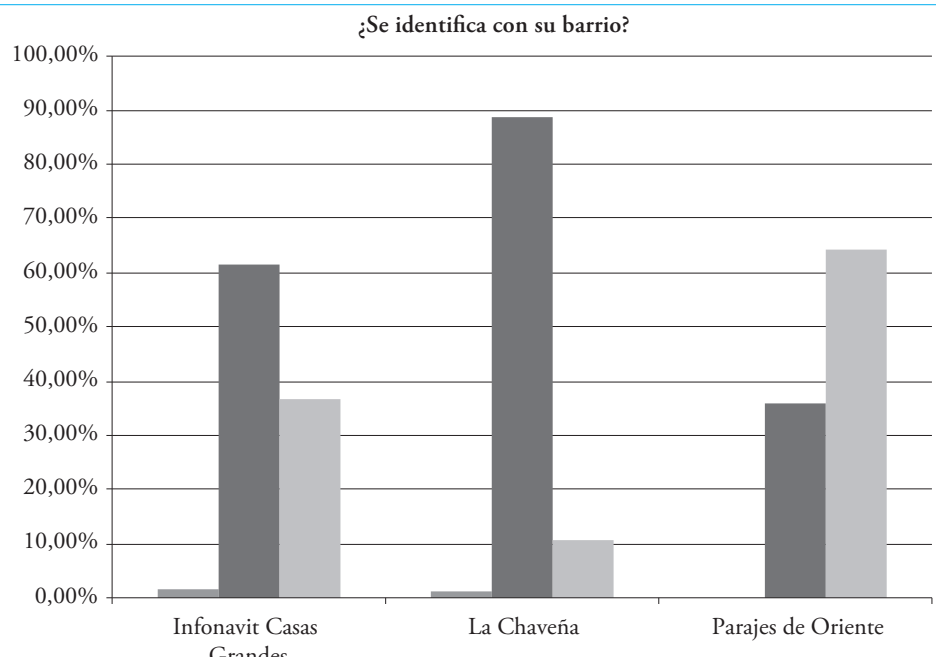

No contestó

— Sí

No

\begin{tabular}{|l|c|c|c|}
\hline \multicolumn{1}{|c|}{ Barrio } & No contestó (\%) & Sí (\%) & No (\%) \\
\hline Infonavit Casas Grandes & 1,7 & 61,7 & 36,7 \\
\hline La Chaveña & 1,0 & 88,6 & 10,5 \\
\hline Parajes de Oriente & 0,0 & 35,7 & 64,3 \\
\hline
\end{tabular}

¿Le gusta su barrio?

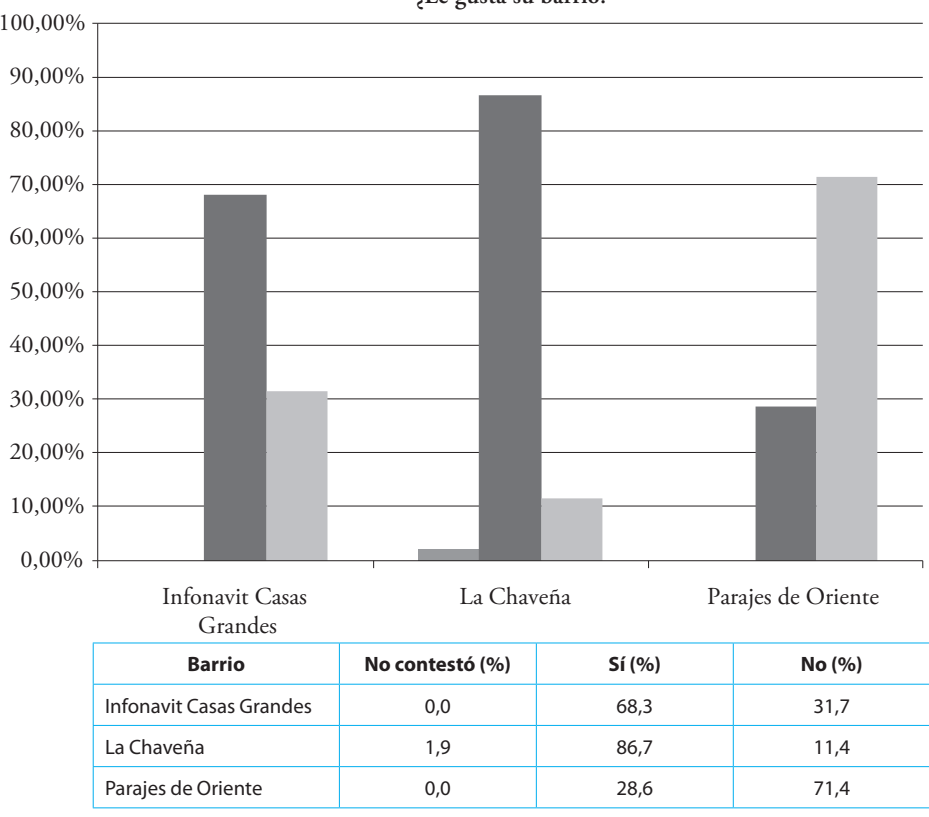




\section{CONCLUSIONES}

Al comparar el planteamiento urbano que dio origen a cada barrio, se observó que a pesar de que los barrios construidos en la zona periférica se sitúan en zonas de la mancha urbana sin restricciones de espacio, se creó una restricción de espacio en el proceso de diseño, lo cual permite señalar deficiencias en el planteamiento de la estructura urbana y los parámetros de densidad en la planificación urbana de la ciudad, lo que inciden negativamente en la sustentabilidad. Así, el tema central que se pretende destacar es el hecho de que un planteamiento inadecuado de la forma urbana (tanto en localización como en diseño) puede afectar la aceptabilidad social de un barrio. Como se ha evidenciado hasta aquí, los planteamientos más recientes de barrios urbanos, como es el caso de Parajes de Oriente, cuentan con deficiencias en términos de morfología urbana y arquitectónica, así como de la dotación de equipamientos y servicios, lo cual disminuye la aceptabilidad social de los mismos e incide negativamente en la sustentabilidad urbana de la ciudad. La localización es un factor que puede favorecer o no la sustentabilidad urbana de modo inmediato, una vez que es un factor clave para minimizar la vulnerabilidad social, como han señalado Morales Cárdenas et al. (2013), en un estudio previo donde se presentaron los resultados de los niveles de seguridad urbana en Ciudad Juárez considerando tres variables: 1) crimen y violencia, 2) desastres naturales y antropogénicos y 3) tenencia de la tierra.

El análisis tuvo a bien el estudiar tres casos diferentes de tipologías de formas urbanas desde la perspectiva urbano-sustentable, que integra los aspectos sociales, económicos y ambientales, dentro de los cuales se abarcan conceptos encargados de dar vida y permitir ciertos patrones de interacción dentro de los diversos barrios seleccionados, donde para los fines del presente artículo se tuvo interacción con habitantes o usuarios de dichas zonas.

Se propone entender más allá de la forma urbana, es necesario cotejar e interrelacionar la comunicación que debería existir y existe entre los usuarios del lugar y los propios aspectos que son creados a través del espacio urbano, el cual abarca factores tales como los espacios verdes y su aceptación, dentro de lo cual es fundamental observar de qué modo se caracteriza, lo que representa, quiénes lo utiliza y si el mantenimiento es el adecuado, ya que tanto influye el que esté en buen estado de conservación, como el que presente vandalismo, así como los aspectos que abarca el considerar el tipo de personas que habitan cada zona, las características socioeconómicas, la aceptabilidad y el equipamiento urbano, el modo en que está compuesto y distribuido, lo cual influye en el modo en el que se darán las interacciones humanas.

En la medida en que se pueda brindar un tipo de planeación urbana "ideal" o "sustentable" que abarque estos aspectos (o al menos la mayoría), estaremos ofreciendo una sensación de bienestar y confort a quienes habiten, paseen o conozcan cada área realizada bajo estos propósitos. Después de entender más de la ciudad y sus células, nuestro compromiso deberá ser ahora promover y proveer este tipo de espacios aptos para el ser humano. 
Es necesario cubrir las necesidades de cada usuario optando por comenzar a menor escala y tratando de uniformizar los criterios que serán capaces de determinar las condiciones de vida urbana, que a su vez beneficien a través de aspectos económicos, sociales y ambientales la calidad de vida. Se requiere conocer y reconocer las necesidades locales, las deficiencias y carencias que cada habitante, usuario, barrio o grupo de la ciudad tiene, a fin de brindar soluciones y oportunidades para cada tipo de interacción entre ellos.

Como se observa en la tabla de conclusiones, si queremos promover una mayor aceptabilidad social de los barrios como camino que nos guíe a un desarrollo más sustentable, es crucial prestar atención y resolver las causas que subyacen a indicadores de insatisfacción o de baja aceptabilidad social, como son el abandono de la vivienda, el poco uso de los espacios públicos, el bajo arraigo o identificación con el barrio y la ciudad, el sentimiento de exclusión.

Se confirma, entonces, la importancia de considerar tanto los aspectos físicos como los sociales para la comprensión del barrio como unidad de análisis. En consonancia con los aspectos señalados, autores como Jenks señalan la necesidad de una comprensión de la aceptación por parte de los usuarios, o

TABLA 1. CONCLUSIONES (SE MARCAN EN GRIS LOS RESULTADOS MÁS ALARMANTES)

\begin{tabular}{|c|c|c|c|c|c|c|}
\hline \multirow{2}{*}{$\begin{array}{c}\text { Localización } \\
\text { Barrio }\end{array}$} & \multicolumn{2}{|l|}{ Central } & \multicolumn{2}{|c|}{ Barrio intermedio } & \multicolumn{2}{|c|}{ Barrio periférico } \\
\hline & La Chaveña (1 & & $\begin{array}{r}\text { Infonavit Casas G } \\
(1980 \mathrm{~s})\end{array}$ & ndes & $\begin{array}{l}\text { Infonavit Parajes d } \\
\qquad(2006)\end{array}$ & riente \\
\hline Variables & Forma urbana & $\begin{array}{l}\text { Acept. } \\
\text { Social } \\
(\%)\end{array}$ & Forma urbana & $\begin{array}{l}\text { Acept. } \\
\text { Social } \\
(\%)\end{array}$ & Forma urbana & $\begin{array}{l}\text { Acept. } \\
\text { Social } \\
(\%)\end{array}$ \\
\hline Población total & 5603 habitantes & & 12.334 habitantes & & 17.206 habitantes & \\
\hline Superficie en hectáreas & $70,9 \mathrm{Ha}$ & & $116,1 \mathrm{Ha}$ & & $155,08 \mathrm{Ha}$ & \\
\hline Densidad población bruta & $79 \mathrm{hab} / \mathrm{ha}$ & & 106 hab / ha & & 110,9 hab/ha & \\
\hline Mayor rango de edad & $45-60$ años $(23,8 \%)$ & & $26-35$ años $(28,3 \%)$ & & $26-35$ años $(52,7 \%)$ & \\
\hline $\begin{array}{l}\text { Densidad poblacional prome- } \\
\text { dio (PDU) }\end{array}$ & $36-70 \mathrm{hab} / \mathrm{Ha}$ & & 71-106 hab/Ha & & $177-213 \mathrm{hab} / \mathrm{Ha}$ & \\
\hline Hacinamiento & 0.81 hab/cuarto & & 0.66 hab/cuarto & & 1,28 hab/cuarto & \\
\hline Diversidad uso de suelo & Alta & & Media & & Baja & \\
\hline Trazado & $\begin{array}{l}\text { Regular con Calle } \\
\text { principal }\end{array}$ & & $\begin{array}{l}\text { Semiregularcon } \\
\text { curva }\end{array}$ & & $\begin{array}{l}\text { Curvo, alargado, } \\
\text { estrecho (suburbio } \\
\text { americano) }\end{array}$ & \\
\hline Tipos de manzanas & Hasta $4000 \mathrm{~m}^{2}$ & & Hasta $4000 \mathrm{~m}^{2}$ & & $4000-8000 \mathrm{~m}^{2}$ & \\
\hline Tipos de lotes & $\begin{array}{l}120 \mathrm{~m}^{2} \text { (promedio) } \\
150-180 \mathrm{~m}^{2} \\
>250 \mathrm{~m}^{2}\end{array}$ & & $\begin{array}{l}120 \mathrm{~m}^{2} \text { (promedio) } \\
150-180 \mathrm{~m}^{2} \\
>250 \mathrm{~m}^{2} \text { (verde) }\end{array}$ & & $\begin{array}{l}120 \mathrm{~m}^{2} \text { (promedio) } \\
150-180 \mathrm{~m}^{2} \\
>250 \mathrm{~m}^{2} \text { (verde) }\end{array}$ & \\
\hline
\end{tabular}




\begin{tabular}{|c|c|c|c|c|c|c|}
\hline Localización & Central & & Barrio intern & & Barrio perife & \\
\hline Barrio & La Chaveña ( & & $\begin{array}{r}\text { Infonavit Casas } \\
\text { (1980s) }\end{array}$ & indes & $\begin{array}{r}\text { Infonavit Parajes } \\
\text { (2006) }\end{array}$ & Priente \\
\hline Variables & Forma urbana & $\begin{array}{l}\text { Acept. } \\
\text { Social } \\
(\%)\end{array}$ & Forma urbana & $\begin{array}{l}\text { Acept. } \\
\text { Social } \\
(\%)\end{array}$ & Forma urbana & $\begin{array}{l}\text { Acept. } \\
\text { Social } \\
(\%)\end{array}$ \\
\hline Equipamiento urbano & $\begin{array}{l}\text { Guardería: } 0 \\
\text { Preescolar: } 2 \\
\text { Primaria: } 4 \\
\text { Secundaria: } 1 \\
\text { Preparatoria: } 2 \\
\text { C. comunitario: } 1 \\
\text { Merc. informal: } 1 \\
\text { Parques: } 2 \\
\text { Hospital: } 1\end{array}$ & & $\begin{array}{l}\text { Guardería: } 2 \\
\text { Preescolar: } 1 \\
\text { Primaria: } 2 \\
\text { Secundaria: } 2 \\
\text { Preparatoria: } 1 \\
\text { C. comunitario: } 1 \\
\text { Merc. informal: } 2 \\
\text { Parques: } 7 \\
\text { Hospital: } 1\end{array}$ & & $\begin{array}{l}\text { Guardería: } 0 \\
\text { Preescolar: } 2 \\
\text { Primaria: } 2 \\
\text { Secundaria: } 0 \\
\text { Preparatoria: } 0 \\
\text { C. comunitario: } 0 \\
\text { Merc. informal: } 0 \\
\text { Parques: baldíos } \\
\text { Hospital: } 0\end{array}$ & \\
\hline Total de vivienda (INEGI) & 1336 & & 4400 & & 5349 & \\
\hline $\begin{array}{l}\text { Densidad de viviendas pro- } \\
\text { medio }\end{array}$ & 18,8 Viv / ha & & 37,9 Viv / ha & & $34,5 \mathrm{Viv} / \mathrm{ha}$ & \\
\hline Vivienda abandonada (INEGI) & & 410 & & 603 & & 1132 \\
\hline $\begin{array}{l}\text { Porcentaje de abandono vi- } \\
\text { vienda (INEGI) }\end{array}$ & & 30,6 & & 13,7 & & 21,6 \\
\hline $\begin{array}{l}\text { Deseo de mudarse (según } \\
\text { encuestados) }\end{array}$ & & 24,8 & & 36,7 & & 70,3 \\
\hline $\begin{array}{l}\text { Viviendas con } 3 \text { o más recáma- } \\
\text { ras (según encuestados) }\end{array}$ & & 89,7 & & 94,9 & & 60,4 \\
\hline $\begin{array}{l}\text { Porcentaje de vivienda en ren- } \\
\text { ta (según encuestados) }\end{array}$ & & 21 & & 11,7 & & 7,1 \\
\hline $\begin{array}{l}\text { SI le gustan espacios públicos } \\
\text { del barrio (según encuestados) }\end{array}$ & & 67,6 & & 53,3 & & 13,7 \\
\hline $\begin{array}{l}\text { NO le gustan espacios públicos } \\
\text { del barrio (según encuestados) }\end{array}$ & & 32,4 & & 46,7 & & 84,6 \\
\hline $\begin{array}{l}\text { Insatisfacción con calles, ban- } \\
\text { quetas, baldíos (según encues- } \\
\text { tados) }\end{array}$ & & 61 & & 46,7 & & 81,3 \\
\hline $\begin{array}{l}\text { Gasto diario en transporte > } 21 \\
\text { pesos (según encuestados) }\end{array}$ & & 47,7 & & 81,7 & & 84,4 \\
\hline $\begin{array}{l}\text { Identificación con el barrio } \\
\text { (según encuestados) }\end{array}$ & & 88,6 & & 61,7 & & 35,7 \\
\hline $\begin{array}{l}\text { Le gusta su barrio (según en- } \\
\text { cuestados) }\end{array}$ & & 86,7 & & 68,3 & & 28,6 \\
\hline $\begin{array}{l}\text { Sentimiento de exclusión (se- } \\
\text { gún encuestados) }\end{array}$ & & 14,3 & & 18,3 & & 50,5 \\
\hline
\end{tabular}

Fuente: elaboracion propia. 
sea desde el punto de vista social, de los elementos que caracterizan la forma urbana de los espacios que usan cotidianamente, ya sea el barrio, el lugar de trabajo o para el ocio, sobre todo en los abordajes que parten de la sustentabilidad urbana: "Las formas urbanas no puede ser consideradas como 'sustentables' en toda la extensión, si estas no son aceptadas por la gente como espacios para vivir, trabajar e interactuar" (Jenks y Colin, 2010).

Se resalta que el espacio presentado como barrio, además de los aspectos físicos y formales, debe promover unidad e interacción, donde más que un espacio de transición sea un lugar de apego y de promoción de relaciones sociales, trabajando a la par la forma urbana del mismo con la aceptación de la gente que vive, trabaja o usa de ella.

Estudiar la sustentabilidad urbana desde el barrio como unidad de análisis básica fue un ejercicio muy fértil, que nos permite apuntar estrategias de desarrollo urbano sustentable para Ciudad Juárez, tanto a nivel de planeación urbana como del diseño urbano de los barrios que puedan promover una mayor aceptabilidad social de los barrios y de la ciudad. En términos de planeación urbana proponemos cinco estrategias clave para alcanzar una mayor aceptabilidad social en Ciudad Juárez:

1. Localización del barrio en zonas de la mancha urbana que tengan capacidad de acogida para el uso de suelo de vivienda y ofrezcan una vida urbana de calidad.

2. Definición de parámetros de densidad poblacional sustentables y propios a cada zona de la ciudad, que sigan como prin- cipio el respeto a los anillos de densidad decreciente desde el centro a la periferia, con el propósito de redensificar las zonas de centralidad y proteger el equilibrio ecológico en los límtes de la ciudad, que la separan del campo y áreas rurales.

3. Cantidad y diversidad adecuada en la dotación de equipamiento público que garantice la equidad de atención de necesidades sociales.

4. Usos de suelo diversos, que permita el desarrollo del comercio y la recreación al interior de cada barrio, así como la implantación de mercados formales e informales para promover la economía de barrio, lo cual le permite al residente tener un acceso a bienes y servicios dentro de su mismo barrio, sin necesidad de invertir mucho tiempo o dinero para poder satisfacer sus necesidades básicas $\mathrm{y}$ recreativas.

5. Transporte público cercano, con opciones de trasbordo que permitan la accesibilidad y movilidad satisfactoria a toda la ciudad sin menoscabar la economía y el tiempo familiar, hecho que los expone a la vulnerabilidad social.

En términos del diseño urbano al interior de los barrios proponemos ocho estrategias claves que permitan promover la aceptabilidad social en Ciudad Juárez desde la escala del barrio:

1. Promover mayor interacción social y uso de los espacios públicos, a través de una mayor diversidad de usos de suelo, de la dotación de equipamiento público y 
de áreas verdes adecuadas, así como del adecuado diseño de los espacios públicos (banquetas, calles, plazas, parques, canchas, estacionamientos, hitos, monumentos), cuidando especialmente la seguridad y confort en el espacio urbano.

2. Promover la pluralidad y diversidad de familias, creando comunidades con familias de distintos niveles de ingreso y evitar las colonias guetto de viviendas de interés social.

3. Evitar el hacinamiento, promoviendo la construcción de distintos tipos de viviendas, con diferente número de recámaras o con posibilidades de ampliación según la necesidad familiar.

4. En colonias de alta densidad, evitar especialmente el hacinamiento, ya que la unión de estas dos variables está íntimamente relacionada con altos niveles de abandono de vivienda.

5. Promover mayor diversidad tipológica de la vivienda para promover una mayor identificación social con su casa y con su barrio, como elementos muy sensibles para la aceptabilidad social.

6. Promover un trazado urbano de calles, manzanas y lotes que favorezca el desplazamiento y la interacción social, accesibilidad, movilidad, seguridad, fluidez. Una forma urbana más próxima a las dinámicas familiares de la familia mexicana, dando preferencia a trazos regulares o semirregulares, con cuadras de no más de 100 metros de largo y con suficiente espacio verde cercano; se de- ben evitar diseńos parecidos al suburbio norteamericano, especialmente cuando se trate de colonias de nivel medio y bajo de ingresos, que dependen de la calidad del transporte colectivo y de la movilidad peatonal.

7. Dotar a cada barrio de una imagen urbana propia, que lo distinga de los demás barrios de la ciudad. El papel de la imagen urbana y la percepción del barrio influyen en la aceptación del mismo, así como en su preservación, sobre todo cuando se cuenta con la presencia de íconos, es por ello que es necesario también el proveer espacios públicos urbanos agradables y accesibles, suprimiendo lotes baldíos y contando con calles limpias y pavimentadas, evitando así contaminación ambiental y visual.

8. Interacción y comunicación del habitante del lugar con los desarrolladores de vivienda, con la finalidad de satisfacer requerimientos básicos que no sean considerados dentro de los planes de desarrollo y que podrían incidir en un desapego del lugar. Es necesario que ambas partes involucradas en los proyectos (además de las normativas y jurídicas partícipes dentro del mismo) pacten en la preservación de los equipamientos dotados; como se evidenció en párrafos anteriores, la calidad de los espacios públicos, ya sean abiertos o cerrados, influye en la percepción y el apego del residente a su barrio y, por ende, en su mantenimiento y conservación. 


\section{REFERENCIAS}

Andruscavage, R. (2007). Arcology optimization and simulation framework [thesis submitted to the faculty of the graduate school of the University of Maryland, College Park, in partial fulfillment of the requirements for the degree of systems engineering master of science].

Bazant, J. (2008). Espacios urbanos, historia, teoría y diseño. México: Limusa.

Brundtland, G. H. (1987). "Nuestro futuro común". Nueva York: Naciones Unidas - Comisión Mundial para el Medio Ambiente y el Desarrollo.

Capel , H. (2002). La morfología de las ciudades. I. Sociedad, cultura y paisaje urbano. Madrid: Ediciones del Serbal.

Castillo Villanueva, L. (2009). Urbanización, problemas ambientales y calidad de vida urbana. México: Plaza y Valdés.

Foladori, G. y Tommasino, H. (2000). El concepto de desarrollo sustentable treinta años después. Desenvolvimento e Meio Ambiente, 1, 41-56.

Hernández Sampieri, R., Fernández Collado, C. y Baptista Lucio, P. (2010). Metodología de la investigación. México: McGraw Hill.

Instituto Municipal de Investigación y Planeación (IMIP) (2010). Plan de Desarrollo Urbano para Ciudad Juárez. Ciudad Juárez: cimip.

Jenks, M. y Burgess, R. (2000). Compact Cities: Sustainable Urban Forms for Developing Countries. New York: Spon Press.

Jenks, M. y Jones, C. (2010). Compact Dimensions of sustainable city. New York: Springer science +business media.
López, V. (2008). Sustentabilidad y desarrollo sustentable, origen, precisiones conceptuales y mitología operativa. México D.F.: Trillas.

Maihold, G. y Urquidi, V. (1990). Diálogo con nuestro futuro común. Perspectivas latinoamericanas del informe de Brundland. Caracas: Editorial Nueva Sociedad.

Miles, M., Hall, T. y Borden, I. (2004). The city cultures reader ( 2 ed.). New York: Routledge.

Morales Cárdenas, S. (2011). La planificación urbana y la prevención de la inseguridad urbana: retos para la normativa e instituciones en Ciudad Juárez. [Tesis de Maestría en Planificación y Desarrollo Urbano].

Moreno, N. (2008). Barrios de Santiago, ¿ruptura o continuidad? Seminario de investigación.

Novaes, E., Vieira, A., Ziccardi, A., Robirosa, M., Lacy, R., Carrion, D. et al. (1996). Segundo foro del Ajusco. El desarrollo sustentable y las metrópolis latinoamericanas. México D.F.: El Colegio de México.

Rapoport, A. (1978). Aspectos de la forma urbana: hacia una confrontación de las ciencias sociales con el diseño de la forma urbana. Barcelona: Gustavo Gili.

Sachs, I. (1994). Estratégias de transiçāo para o século XXI Cadernos de Desenvolvimento e Meio Ambiente. Curitiba: Editora UFPR.

Soleri, P. (1969). Arcology - City in the Image of Man. Cambridge: MIт Press.

Soleri, P. (1987). Arcosanti, An urban laboratory? Cambridge: vTi Press. 